\title{
Individuals' perceptions and information sources on vaccination in Greece
}

\author{
Paraskevi E. Skarpa ${ }^{1}$, Emmanouel Garoufallou ${ }^{1}$
}

\section{AFFILIATION}

1 Department of Library Science, Archives and Information Systems, School of Social Sciences, International Hellenic University, Thessaloniki, Greece

\section{CORRESPONDENCE TO}

Emmanouel Garoufallou. Department of Library Science, Archives and Information Systems, School of Social Sciences, International Hellenic University, P.O. BOX 141, GR-57400, Thessaloniki, Greece.
Email: mgarou@ihu.gr

ORCID ID: https://orcid.org/0000-0001-8232-6634

\section{KEYWORDS}

information, vaccine-preventable diseases, vaccination, public health, vaccine hesitancy, vaccine safety, libraries, documentation centers

Received: 9 May 2021, Revised: 20 January 2022,

Accepted: 21 January 2022

https://doi.org/10.18332/popmed/146003
RESULTS Responses by 683 individuals were obtained. Healthcare professionals are considered by the participants as the preferred source of information on vaccination. Older age groups express a higher degree of agreement regarding doctors as preferred information source, compared to the younger ones. More than $60 \%$ of the participants choose to be informed by official bodies such as the National Public Health Organization, the Ministry of Health, the WHO and the European Centre for Disease Prevention and Control. A small proportion of the respondents (8\%) stated that often to always they preferred social media as information sources about vaccinations. Doctors and Ministry of Health as sources of information and older age groups were found to be strong predictors of participants' positive attitude towards vaccines. CONCLUSIONS The study revealed that the vast majority of the participants are positive about vaccinations and seem to rely on more official sources of information on vaccination than the general Internet and social media. Communication efforts on vaccination awareness should be directed at younger ages and in particular through social media.

\section{INTRODUCTION}

In the digital age, Internet and social networks are the most important media of exchanging information and personal experiences. They play an important role in informing individuals in many areas, including the field of Health ${ }^{1,2}$. Individuals with health problems can use social media to increase their knowledge about diseases and treatment; often using the Internet as their main source of information, possibly disrupting the patient-doctor relationship, especially with regard to chronic diseases that require ongoing treatment ${ }^{3}$. In addition, misinformation on health- related issues that spreads on the Internet and social media can have negative consequences ${ }^{4}$.

The Internet and social media have become tools for seeking health information and vaccinations in particular ${ }^{5}$. The increased presence of anti-vaccine content on social media presumably reduces vaccine uptake, thus increasing vaccine-preventable diseases ${ }^{6}$.

Vaccines have been classified as one of the most important discoveries of all time ${ }^{7}$. It is estimated that they save two to six million lives each year, furthermore an additional one and a half million people could survive if vaccination coverage 
was adequately increased ${ }^{8}$.

Despite the availability of safe and effective vaccines, several European countries are experiencing cases of vaccine preventable diseases for a variety of reasons. Many parents may experience difficulties accessing the healthcare system or be unaware of the need or means to prevent them ${ }^{9}$. Some groups of individuals show reduced trust in governments and others are encouraged to undermine existing trust. This requires new approaches, recognizing that the conventional approach and persuasion of these groups can have the opposite result.

Vaccination programs are based on a high level of population coverage in order to be successful in reducing the prevalence of vaccine-preventable diseases ${ }^{10}$. For example, the WHO aimed to eradicate measles worldwide by 2007 and recommended vaccination of more than $95 \%$ of the population ${ }^{10}$. However, the global average population coverage was $86 \%$ in $2018^{8}$. That children are still dying from measles, for which an effective vaccine has existed for almost 60 years, reflects a crisis in both the provision of public health services and the public's understanding of science ${ }^{9}$.

The decline in public confidence in vaccination is a global phenomenon ${ }^{11}$. Many possible explanations for this decrease have been suggested, including fears about vaccine safety, the rise of the anti-vaccination movements, the use of social media, and growing distrust of expert opinion.

Vaccine hesitancy has been characterized by the WHO as one of the ten global health threats in 2019. It is a threat to the progress made in defeating vaccine-preventable diseases ${ }^{8}$.

Health literacy skills could help individuals to prevent or to eliminate diseases by accepting measures such as vaccination, especially for vulnerable populations. Health information literacy is the degree to which individuals are able to use correctly sources of information when making informed decisions about their health. It supposes a level of knowledge, personal skills and confidence to act in order to improve personal health and society as a whole, through changes in personal lifestyle and living conditions ${ }^{12}$.

Scientists are the most competent to share scientific knowledge with the public in order to help them make informed decisions. Adapting to the new era and increasing the use of widespread digital tools in our rapidly evolving society are needed to restrict the gap between the means by which scientific and official information is available and the tools individuals use for information seeking ${ }^{13}$.

Previous studies have thoroughly investigated vaccination uptake in Greece, for example, concerning the national vaccination program ${ }^{14}$, measles ${ }^{9}, \mathrm{HPV}^{15}$, hepatitis $\mathrm{A}$, influenza ${ }^{16}$, and COVID-19 ${ }^{17}$. However, to the best of our knowledge, vaccination uptake by the general population has not been associated with its information sources on vaccines. Therefore, the present study investigated the general public's perceptions on vaccination and their sources of information on vaccines, in Greece.

\section{METHODS}

This study was conducted through a web-based survey. The data collection was facilitated by the use of questionnaire posted on the Google Forms platform (https://www.google. com/forms/). The survey questionnaire was disseminated by email, Facebook's Messenger application and the Viber application to about 3000 recipients. The targetaudience was approached by sending messages to e-mail addresses published on official lists on websites of Public Services, Regional Units, associations and other bodies. The questionnaire was also sent through the Viber and Facebook Messager applications to the authors' personal contacts with the request to be communicated to the widest possible audience. Through the duration of the survey, 683 completed questionnaires were obtained.

The research is part of a postgraduate dissertation designed and conducted at the International Hellenic University, School of Social Sciences, Department of Library Science, Archives and Information Systems ${ }^{18}$. The survey, undertaken between 10 April and 15 May 2020, at a period when the COVID-19 pandemic was ongoing, and aimed to investigate the general public's views on vaccination and their information sources about vaccines, in Greece. The questionnaire was divided into two sections: 1) demographic data; and 2) respondents' views and information sources about vaccines.

The questionnaire included closed questions using a 7-point Likert scale and multiple-choice questions. Likert scale responses were: 1 = never, 2 = rarely, 3 = usually not, $4=$ sometimes, $5=$ often, $6=$ very often, and $7=$ always; or 1 = strongly disagree, 2 = disagree, $3=$ partly disagree, $4=$ neither disagree/nor agree, $5=$ partially agree, $6=$ agree, and 7 = strongly agree. This scale was considered to be the most appropriate for capturing respondents' perceptions, as it allows the direction and neutrality to be measured, as well as the estimation of the intensity of perceptions, on three levels (disagreement, neutrality, agreement), thus providing more useful information ${ }^{19}$.

\section{Statistical analysis}

In order to describe the characteristics of the sample and to present the results of the survey, the data were subjected to a descriptive statistical analysis enabling the information to be presented in tables. For the purposes of this work, the results of the questionnaire are interpreted according to the median of the distributions of survey responses as a central tendency measure of the participants' views, because it is considered a more appropriate central tendency measure for ordinal data ${ }^{20,21}$

The Cronbach's alpha reliability coefficient of internal consistency for the scale was calculated and reported.

As the data collected from the questionnaire are ordinal ${ }^{20,21}$, normality assumption is violated under the Shapiro-Wilk criterion and data distributions are strongly skewed due to the 7-point Likert scale used. For these 
reasons the analysis of the data was carried out using nonparametric methods, as recommended in the literature ${ }^{20}$.

Further analysis between genders was performed. The data collected from the questionnaire were analyzed using the non-parametric criterion Mann-Whitney-Wilcoxon (Mann-Whitney U), which compares two independent samples ${ }^{21}$ and is suitable for data with strongly skewed distribution, such as those derived from the 7-point Likert scale used in this survey ${ }^{20}$.

In addition, in cases where analysis between age groups was required, the non-parametric criterion KruskalWallis was applied, which controls differences between independent variables and is not affected by outliers and the existence of skewed distributions ${ }^{21}$. In the case of a statistically significant difference being found under the Kruskal-Wallis criterion, the Dunn post hoc test was applied for further analysis, in order to determine the existence of specific differences between variables.

Bivariate logistic regression was performed to explore any potential predictor variable concerning information sources on the participants' opinions on vaccines. Odds ratios (ORs) and $95 \%$ confidence intervals (CIs) are presented. For the purpose of the analysis, variables were dichotomized into 'in favor' (partially agree, agree and strongly agree), and 'not in favor' (strongly disagree, disagree, partially disagree, and neither disagree/nor agree), following Mathieu et al. ${ }^{22}$. The analyses were performed using the open source statistical analysis software Jasp 0.14.1 (University of Amsterdam).

\section{RESULTS}

\section{Characteristics of survey participants}

A total of 683 people participated in this study, from all Greek Regions. Most of the participants were female (65\%), had at least a Bachelor's degree and were mainly civil servants or private employees. The age distribution of the participants included $32 \%$ who were aged $13-30$ years, $41 \%$ aged $31-50$ years and $27 \%$ aged $\geq 51$ years (Table 1 ).

\section{Individuals' perceptions on vaccinations}

Analysis of the data showed that the majority of participants $(74.7 \%)$ were vaccinated either themselves, or their children, or another member of their family in the last 5 years. Those who stated that they have not been vaccinated were $19.2 \%$. Finally, $6.1 \%$ of the participants stated that they did not know if any member of their family was vaccinated in the last 5 years.

An optional question asked the participants the reasons for their last vaccination. The results showed that $72.3 \%$ of the participants stated that it was after a doctor's recommendation, $20.4 \%$ a personal decision, $11.0 \%$ declared to be unaware, $4.9 \%$ after the family's recommendation, and $3.7 \%$ for traveling reasons.

Respondents had the option, if relevant, to explain why they had not been vaccinated in the last 5 years. The analysis of the data showed that $70.0 \%$ of the respondents were not vaccinated because there was no need for vaccination, while $36.5 \%$ were still covered by vaccines they received earlier. Some participants (9.5\%) believed that vaccines are not safe and can have side effects and for this reason they were not vaccinated, $8.8 \%$ did not express any opinion, while 3.3\% believed that vaccines are not effective. The results are given in Table 2.

Participants were asked to express their views about the importance of vaccines in a 7-point Likert scale question.

\section{Table 1. Sociodemographic characteristics of the} respondents, Greece, 2020 ( $\mathrm{N}=683$ )

\begin{tabular}{llrc} 
Characteristics & Categories & \multicolumn{1}{c}{ n } & \multicolumn{1}{c}{$\%$} \\
\hline \multirow{4}{*}{ Gender } & Female & 440 & 64.4 \\
& Male & 243 & 35.6 \\
Education level & $13-30$ & 217 & 31.8 \\
& $31-50$ & 279 & 40.8 \\
& $\geq 51$ & 187 & 27.4 \\
& Less than high school & 24 & 3.5 \\
& High school & 56 & 8.2 \\
& Technical education & 45 & 6.6 \\
& Bachelor's degree & 327 & 47.9 \\
& Master's degree & 180 & 26.4 \\
& Doctoral degree & 51 & 7.5 \\
Profession & Civil servants & 246 & 36.0 \\
& Private employees & 151 & 22.1 \\
& University students & 129 & 18.9 \\
& Self-employed & 56 & 8.2 \\
& Unemployed & 49 & 7.2 \\
& Retired & 32 & 4.7 \\
& Farmers & 13 & 1.9 \\
& High school students & 7 & 1.0
\end{tabular}

Table 2. Participant responses* to the question: 'If you haven't had any vaccination in the last five years, why haven't you been vaccinated?', Greece, 2020 ( $\mathrm{N}=400)$

\begin{tabular}{|c|c|c|}
\hline Responses & $\mathbf{n}$ & $\%$ \\
\hline There was no need for vaccination & 280 & 70.0 \\
\hline I am still covered by vaccines I received earlier & 146 & 36.5 \\
\hline $\begin{array}{l}\text { I believe that vaccines are not safe and can } \\
\text { have side effects }\end{array}$ & 38 & 9.5 \\
\hline No comment & 35 & 8.8 \\
\hline I believe that vaccines are not effective & 13 & 3.3 \\
\hline $\begin{array}{l}\text { Someone else decides for me (parents, } \\
\text { guardians) }\end{array}$ & 7 & 1.8 \\
\hline
\end{tabular}

* Multiple choice; optional. 
The Cronbach's alpha reliability coefficient of the scale was 0.939 . The analysis of the data revealed that, in level of central tendency, participants strongly agree with the view that everyone should get the usual vaccines (measles, meningitis, hepatitis, polio). In addition, they agree that vaccines are important for the protection of themselves and society and that refusal to be vaccinated can lead to serious health problems and outbreaks (Table 3 ).

Further analysis using the Mann-Whitney U criterion, failed to reveal any significant difference between genders regarding the intensity of their beliefs about the importance of vaccination, at a significance level of 0.05 . The KruskalWallis test shows that there is a significant difference in the intensity of beliefs between participants aged $>30$ years (age groups $31-50$ and $\geq 51$ years) and younger ones. Participants aged $>30$ years express relatively higher intensity of agreement on the position that all people should get the usual vaccines $(\mathrm{H}=12.975 ; \mathrm{df}=2 ; \mathrm{p}=0.002)$, that vaccines are considered important for their protection $(\mathrm{H}=21.697$; $\mathrm{df}=2 ; \mathrm{p}<0.001)$, as well as community protection $(\mathrm{H}=23.558$; $\mathrm{df}=2 ; \mathrm{p}<0.001$ ). Moreover, respondents over 30 years of age express also relatively higher intensity of agreement on the view that refusal of vaccination can lead to serious problems $(\mathrm{H}=18.094 ; \mathrm{df}=2 ; \mathrm{p}<0.001)$, as well as pandemic for the community $(\mathrm{H}=23.801 ; \mathrm{df}=2 ; \mathrm{p}<0.001)$.

Respondents were asked to answer a multiple-choice question on infectious diseases that continue to cause deaths in the European Union (EU) today. Participants declared influenza $(85.2 \%)$ as the disease that causes deaths in the EU more often, followed by COVID-19 (82.7\%), meningitis (50.1\%), hepatitis (45.5\%), polio (21.1\%), measles (19.0\%) and tetanus (15.5\%).

Participants were asked to share their beliefs regarding the safety and efficacy of vaccines. Scale reliability Cronbach's $\alpha=0.799$. The analysis of the data showed that, at a central tendency level, participants agree that vaccines are rigorously tested before being authorized, that they protect people from serious diseases and that they are important for children and vulnerable groups. They partly agree that many actions to spread certain new vaccines are aimed at financial gain. In addition, regarding the view that vaccines often cause side effects, neutrality was recorded, while they disagree with the statement that vaccines are not important to themselves (Table 4).

Further analysis following the Mann-Whitney U criterion reveals that there are statistically significant differences in the intensity of beliefs between genders, regarding testing of vaccines before their approval (males express a significantly higher intensity of agreement; $\mathrm{W}=59815.0 ; \mathrm{p}=0.008$ ), whether vaccines often cause side effects (females have a significantly higher degree of agreement; $\mathrm{W}=45814.0$; $\mathrm{p}=0.001$ ) and the view that many actions to spread some new vaccines are aimed at financial gain (females have a significantly higher degree of agreement; $\mathrm{W}=43774.0$; $\mathrm{p}<0.001$ ).

Moreover, after the Kruskal-Wallis criterion was applied, it was found that participants under the age of 30 years expressed a significantly lower degree of agreement regarding the position that vaccines are rigorously tested before being authorized, compared to participants aged $>30$ years $(\mathrm{H}=8.030 ; \mathrm{df}=2 ; \mathrm{p}=0.018)$. Regarding the importance of vaccines to children is concerned, a statistically significant difference was found between participants aged $>30$ years, who expressed a significantly higher degree of agreement compared to participants aged $\leq 30$ years $(H=16.490$; $d f=2$, $\mathrm{p}<0.001)$. A similar statistically significant difference was found concerning the statements that vaccines are important for vulnerable groups $(\mathrm{H}=14.103 ; \mathrm{df}=2 ; \mathrm{p}<0.001)$ and vaccines protect against serious diseases $(\mathrm{H}=17.592 ; \mathrm{df}=2$; $\mathrm{p}<0.001$ ). Conversely, concerning the view that many actions for the dissemination of certain new vaccines are aimed at financial gain, participants aged $\leq 30$ years have a relatively

Table 3. Participants' response frequencies regarding their views on the importance of vaccination, Greece, 2020 $(\mathrm{N}=683)$

\begin{tabular}{|c|c|c|c|c|c|c|c|c|}
\hline Views & $\begin{array}{l}\text { Strongly } \\
\text { disagree }\end{array}$ & Disagree & $\begin{array}{l}\text { Partly } \\
\text { disagree }\end{array}$ & $\begin{array}{l}\text { Neither } \\
\text { disagree/ } \\
\text { nor agree }\end{array}$ & $\begin{array}{l}\text { Partly } \\
\text { agree }\end{array}$ & Agree & $\begin{array}{l}\text { Strongly } \\
\text { agree }\end{array}$ & Median \\
\hline $\begin{array}{l}\text { All people should get the usual } \\
\text { vaccines (measles, meningitis, } \\
\text { hepatitis, polio) }\end{array}$ & 5 & 6 & 14 & 35 & 60 & 191 & 372 & 7 \\
\hline $\begin{array}{l}\text { Vaccines are important for my } \\
\text { protection }\end{array}$ & 4 & 5 & 11 & 41 & 94 & 210 & 318 & 6 \\
\hline $\begin{array}{l}\text { Refusal to be vaccinated can lead } \\
\text { to serious health problems }\end{array}$ & 4 & 14 & 31 & 67 & 96 & 194 & 277 & 6 \\
\hline $\begin{array}{l}\text { Refusal to be vaccinated can lead } \\
\text { to an epidemic }\end{array}$ & 8 & 21 & 37 & 84 & 103 & 190 & 240 & 6 \\
\hline $\begin{array}{l}\text { Vaccines are important for } \\
\text { protecting society }\end{array}$ & 4 & 9 & 24 & 62 & 94 & 196 & 294 & 6 \\
\hline
\end{tabular}


higher degree of agreement compared to participants aged $>30$ years $(\mathrm{H}=12.599$; $\mathrm{df}=2, \mathrm{p}=0.002)$.

\section{Information sources}

Finally, participants were asked to declare their information sources about vaccination in a 7-point Likert scale question. The Cronbach's $\alpha$ reliability coefficient of the scale was 0.894 . The results are presented in Table 5. In terms of central tendency participants get informed on vaccination issues always by their doctor, very often by other health workers, their pharmacist, the National Public Health Organization (https://eody.gov.gr), the Ministry of Health (http://www. moh.gov.gr) and the WHO. They also choose sometimes to be informed by the European Center for Disease Prevention and Control, by their friends and family, usually not from general Internet (i.e. personal websites or blogs), rarely from libraries, radio and newspapers. Finally, the majority of the participants declared that they never get informed by social networks about vaccinations (e.g. Facebook 65.0\%, YouTube $74.8 \%$, Twitter $77.8 \%$ ).

Further analysis reveals that there are statistically significant differences between genders concerning their responses in relation to information sources on vaccines. The Mann-Whitney U criterion shows that males seem to express a greater degree of preference, compared to females, to get informed on vaccination by the printed press ( $\mathrm{W}=64498.5 ; \mathrm{p}<0.001)$, electronic press $(\mathrm{W}=59066.5$; $\mathrm{p}=0.020)$, radio $(\mathrm{W}=63723.0 ; \mathrm{p}<0.001)$, and television $(\mathrm{W}=61752.5 ; \mathrm{p}<0.001)$. In contrast, females seem to show a higher preference, compared to males, to get informed on vaccination by healthcare workers $(\mathrm{W}=47048.0 ; \mathrm{p}=0.007)$ and the WHO (W=48461.5; $\mathrm{p}=0.038$ ).

Moreover, analysis shows that there is statistically significant difference among the three age groups on their preference to be informed on vaccination by printed press (Kruskal-Wallis test; $\mathrm{H}=26.802$; $\mathrm{p}<0.001$ ). The older participants (aged $\geq 51$ years) seem to be informed more frequently by printed press compared to the younger ones (13-30 and 31-50 years) (Dunn's post hoc test, $\mathrm{p}<0.001$ and $\mathrm{p}=0.029$, respectively). Participants in the age group of 31-50 years seem to get informed by printed press more frequently than the younger ones $(13-30$ years $)(p<0.001)$. Similarly, significant differences are observed among age groups concerning radio $(\mathrm{H}=17.830 ; \mathrm{p}<0.001)$ and television $(\mathrm{H}=18.875 ; \mathrm{p}<0.001)$. The older participants (aged $\geq 51$ years) seem to be informed more frequently by radio compared to the younger ones (13-30 and 31-50 years; $\mathrm{p}<0.001$ and $\mathrm{p}=0.006$, respectively), as well as television ( $p<0.001$ and $p=0.002$, respectively). Also, participants aged 31-50 years seem to get informed more frequently by radio $(\mathrm{p}=0.021)$ and television $(\mathrm{p}=0.034)$, compared to the younger ones (13-30 years).

After performing bivariate logistic regression analysis using a stepwise method concerning sociodemographic predictors and preferred information sources on vaccines, it was found that participants favored the view that all people should get the usual vaccines if they were aged $>31$ years $(\mathrm{OR}=2.77$; 95\% CI: 1.57-4.88, $\mathrm{p}<0.001)$. Getting informed by doctor $(\mathrm{OR}=4.32$; $95 \% \mathrm{CI}: 2.25-8.27, \mathrm{p}<0.001)$ or Ministry of Health (OR=2.41; 95\% CI: $1.34-4.34, \mathrm{p}=0.003)$ were factors affecting positively concerning the above perception. In contrast, participants did not hold this view if they were informed by Facebook (OR=0.35; 95\% CI: 0.13-0.92, $\mathrm{p}=0.034)$. Concerning the view that vaccines often cause side effects, female gender $(\mathrm{OR}=1.76$; $95 \% \mathrm{CI}: 1.27-2.44$, $\mathrm{p}<0.001)$, YouTube (OR=3.13; 95\% CI: 1.30-7.53, $\mathrm{p}=0.011$ ), Internet (OR=1.89; 95\% CI: 1.27-2.81, $\mathrm{p}=0.002)$, holding

Table 4. Participants' response frequencies regarding their views on the safety and efficacy of vaccination Greece, $2020(\mathrm{~N}=683)$

\begin{tabular}{|c|c|c|c|c|c|c|c|c|}
\hline Views & $\begin{array}{l}\text { Strongly } \\
\text { disagree }\end{array}$ & Disagree & $\begin{array}{c}\text { Partly } \\
\text { disagree }\end{array}$ & \begin{tabular}{|c|} 
Neither \\
disagree/ \\
nor agree
\end{tabular} & $\begin{array}{l}\text { Partly } \\
\text { agree }\end{array}$ & Agree & $\begin{array}{l}\text { Strongly } \\
\text { agree }\end{array}$ & Median \\
\hline $\begin{array}{l}\text { Vaccines are rigorously tested } \\
\text { before they are approved for use }\end{array}$ & 4 & 20 & 30 & 107 & 137 & 252 & 133 & 6 \\
\hline Vaccines are not important to me & 219 & 212 & 74 & 93 & 39 & 28 & 18 & 2 \\
\hline Vaccines often cause side effects & 25 & 78 & 106 & 146 & 221 & 90 & 17 & 4 \\
\hline $\begin{array}{l}\text { Vaccines are important for } \\
\text { children }\end{array}$ & 3 & 4 & 8 & 39 & 81 & 258 & 290 & 6 \\
\hline $\begin{array}{l}\text { Vaccines are important for } \\
\text { vulnerable groups }\end{array}$ & 2 & 5 & 5 & 39 & 82 & 234 & 316 & 6 \\
\hline $\begin{array}{l}\text { Vaccines protect people from } \\
\text { serious diseases }\end{array}$ & 3 & 8 & 11 & 52 & 91 & 248 & 270 & 6 \\
\hline $\begin{array}{l}\text { Many actions to spread certain } \\
\text { new vaccines are aimed at } \\
\text { financial gain }\end{array}$ & 20 & 54 & 45 & 124 & 172 & 158 & 110 & 5 \\
\hline
\end{tabular}


Table 5. Participants' response frequencies regarding their information sources preference on vaccination Greece, $2020(\mathrm{~N}=683)$

\begin{tabular}{|c|c|c|c|c|c|c|c|c|}
\hline Sources & Never & Rarely & $\begin{array}{c}\text { Usually } \\
\text { not }\end{array}$ & Sometimes & Often & $\begin{array}{l}\text { Very } \\
\text { often }\end{array}$ & Always & Median \\
\hline Press & 269 & 115 & 80 & 88 & 50 & 58 & 23 & 2 \\
\hline Radio & 285 & 111 & 83 & 81 & 49 & 59 & 15 & 2 \\
\hline Television & 232 & 102 & 71 & 108 & 67 & 77 & 26 & 3 \\
\hline Electronic press & 223 & 68 & 63 & 108 & 94 & 97 & 30 & 3 \\
\hline $\begin{array}{l}\text { General Internet (i.e. personal } \\
\text { websites or blogs) }\end{array}$ & 243 & 77 & 61 & 102 & 81 & 88 & 31 & 3 \\
\hline Facebook & 447 & 81 & 52 & 46 & 27 & 25 & 5 & 1 \\
\hline Twitter & 531 & 69 & 39 & 25 & 7 & 9 & 3 & 1 \\
\hline Instagram & 536 & 69 & 40 & 21 & 7 & 6 & 4 & 1 \\
\hline YouTube & 511 & 71 & 36 & 34 & 13 & 15 & 3 & 1 \\
\hline Reddit & 564 & 54 & 33 & 19 & 4 & 7 & 2 & 1 \\
\hline Pinterest & 566 & 55 & 31 & 21 & 2 & 6 & 2 & 1 \\
\hline WhatsApp & 564 & 54 & 31 & 18 & 6 & 8 & 2 & 1 \\
\hline Doctor & 23 & 16 & 8 & 27 & 30 & 118 & 461 & 7 \\
\hline Healthcare workers & 59 & 24 & 31 & 53 & 96 & 206 & 214 & 6 \\
\hline Pharmacist & 55 & 31 & 40 & 61 & 122 & 218 & 156 & 6 \\
\hline Family & 120 & 64 & 66 & 119 & 142 & 118 & 54 & 4 \\
\hline Friends & 173 & 76 & 89 & 113 & 135 & 76 & 21 & 4 \\
\hline Library & 315 & 88 & 73 & 75 & 55 & 50 & 27 & 2 \\
\hline $\begin{array}{l}\text { National Public Health } \\
\text { Organization }\end{array}$ & 77 & 39 & 35 & 72 & 79 & 163 & 218 & 6 \\
\hline Ministry of Health & 77 & 39 & 34 & 71 & 90 & 171 & 201 & 6 \\
\hline $\begin{array}{l}\text { European Centre for Disease } \\
\text { Prevention and Control (ECDC) }\end{array}$ & 120 & 41 & 40 & 72 & 81 & 146 & 183 & 5 \\
\hline WHO & 95 & 39 & 38 & 73 & 83 & 145 & 210 & 6 \\
\hline
\end{tabular}

university or higher degree (OR=0.59; 95\% CI: $0.39-0.89$, $\mathrm{p}=0.012)$ and television (OR=0.52; 95\% CI: $0.34-0.79$, $\mathrm{p}=0.002$ ) were all significantly associated factors. Further statistical analysis is provided in the Supplementary file.

\section{DISCUSSION}

The present study attempted to record the perceived views of the general population in Greece about vaccines and to identify specific demographic characteristics and information sources as factors influencing individuals' attitudes to vaccination.

Among contagious diseases that cause deaths in the $\mathrm{EU}$, influenza is considered by participants to be the most common (85\%), followed by COVID-19 (83\%). Seasonal influenza is still a major cause of death today in the $\mathrm{EU}^{23}$ and globally ${ }^{24}$. Given that the COVID-19 pandemic was ongoing during this investigation, with high numbers of recorded deaths in European countries ${ }^{25}$, a high incidence of selection of the disease was recorded by the participants. Also, meningitis (50\%) and hepatitis (46\%) were declared by the respondents as important contagious diseases causing deaths in EU. Eurobarometer survey on Greek individuals' attitudes towards vaccination found similar results with influenza (87\%), meningitis (57\%) and hepatitis $(47 \%)^{26}$.

Previous studies have shown that healthcare professionals are the most important sources of information on vaccination ${ }^{27,28}$. Our survey results confirm that healthcare professionals in general are considered by the participants as the preferred source of information on vaccination. Doctors are 'often' to 'always' preferred by $89 \%$ of the respondents, followed by other healthcare workers (76\%) and pharmacists (73\%). These findings are consistent with Campbell et al. ${ }^{29}$ and Mathieu et al. ${ }^{22}$ who found that healthcare professionals in general are the most trusted 
source of information in England and France, respectively. According to the Eurobarometer survey ${ }^{26}$ doctors were the preferred source of information on vaccination (94\%) of the participants in Greece, with lower preference for Health Authorities (34\%), other healthcare workers (28\%), and pharmacists $(25 \%)$.

Our findings suggest also that older age groups express a higher degree of agreement regarding doctors as preferable information source, compared to the corresponding younger ones, which is in accordance with the findings of Walter et al. ${ }^{30}$. In addition, more than $60 \%$ of the participants choose to be informed by official bodies such as the National Public Health Organization, the Ministry of Health, the WHO, and the European CDC. Furthermore, 19\% of the participants 'often' to 'always' prefer to get informed on vaccination from libraries. Although our results did not record a high preference of participants to get informed from libraries, it is worth noting that libraries during the recent COVID-19 pandemic took initiatives to inform the public remotely, thus showing that they have a role as a source of valid information. For example, IFLA has published a special COVID-19 edition infographic on the recognition of fake news, with particular emphasis on the need to crossreference information, since much fake news is being distributed on the Internet and on social media ${ }^{31}$. Also, $29 \%$ of the respondents 'often' to 'always' choose general Internet (i.e. personal websites or blogs) as information source on vaccination. It is worth noting that $8 \%$ of the respondents stated that 'often' to 'always' prefer social media as information sources about vaccinations, which is in accordance with Mathieu et al..$^{22}$. Our findings suggest that respondents seem to prefer more reliable sources of information on vaccination than the general Internet and social media. This finding is of importance as Meppelink et $a .^{32}$ confirmed the existence of selective exposure and biased evaluation of information on vaccines in online health communication, and Hwang and $\mathrm{Shah}^{33}$ reported that social media feature a prevalence of concerns, fears and misinformation about vaccines.

In a previous study, Papazoglou et al. ${ }^{14}$ reported that parents in Greece had a greater possibility of having satisfactory knowledge on vaccines if they were informed by doctors, compared to those that did not get any information from doctors. Also, Dardalas et al. ${ }^{16}$ found that greater age and doctors had a positive influence upon the uptake of the vaccines in Greece. Reiter et al. ${ }^{28}$ reported that participants were more likely to be willing to get a COVID-19 vaccine if they were advised by their healthcare provider and less likely to be willing to get vaccinated if they were female, or reported high level of perceived potential side effects of a vaccine. Our results suggest that participants' likelihood of expressing a positive attitude towards vaccines if they were older is $177 \%$ higher compared to younger ones. Similarly, respondents were more likely to be in favor of the statement that all people should get the usual vaccines if they were informed by doctors (332\% higher) or Ministry of Health (141\% higher), compared to those that did not get any information from doctors or Ministry of Health. However, the use of Facebook influences negatively attitudes towards vaccines. Furthermore, female gender, YouTube and the general Internet (personal websites and blogs) use are three factors that positively persuade participants that vaccines often cause side effects, while university or postgraduate degree and television use as information source are negatively associated with this perception. This is in accordance with Mathieu et al. ${ }^{22}$ who have reported that high level of education was positively associated with acceptance of vaccination, as well as with Hwang and Shah ${ }^{33}$ who found strong positive association between television use and perceptions of vaccination benefits.

Participants or their family members have been vaccinated on the basis of a doctor's recommendation with high frequency $(72 \%)$, which is consistent with the Eurobarometer survey (86\%) in Greece ${ }^{26}$. Participants who have not been vaccinated, stated mainly that there was no need for vaccination $(70 \%)$ or that they are covered by previous vaccines (37\%), while in the Eurobarometer survey the corresponding figures are $49 \%$ and $28 \%$, respectively ${ }^{26}$. In a systematic literature review of perceived risks of vaccines in European populations, the belief that vaccines were not necessary was reported as the third most common reason for hesitating to be vaccinated ${ }^{34}$. Furthermore, a minor proportion of participants in our study who were not vaccinated declared that they do not consider the vaccines safe and that they possibly cause side effects (9.5\%), suggesting the presence of a vaccine skeptic sub-group (compared to $12 \%$ of those asked in the Eurobarometer survey) ${ }^{26}$. It is considered that safety, effectiveness and usefulness of vaccines are in the center of growing concerns among individuals that threaten vaccination programs ${ }^{35}$. In a recent study in Greece, Mouchtouri et al. ${ }^{17}$ reported that $18.9 \%$ of respondents stated that they were against getting the COVID-19 vaccine, while Tsagkas et al. ${ }^{15}$ reported that only $3.3 \%$ of the participants were negative about all vaccines. Given that measles has been suggested as an indicator of the immunization status of a population ${ }^{36}$, it is noteworthy that measles continues to be an important public health problem in Greece, as recent studies have identified gaps in the immunization of the general population?.

Most of the participants in our study (91\%) believe that everyone should get the usual vaccines (Eurobarometer survey in Greece: 85\%) $)^{26}$ and $83 \%$ consider that refusing vaccination can lead to serious health problems (Eurobarometer survey in Greece: $82 \%)^{26}$, which indicates that the majority of the participants is positive about the vaccination and confirms the findings of Mouchtouri et al. ${ }^{17}$ who reported that $81 \%$ of Greek people were in favor of COVID-19 vaccination and is also in accordance with other recent European studies ${ }^{22}$.

Most of the participants (76\%) partly to strongly 
agree that vaccines are rigorously tested before they are authorized for use. In the Eurobarometer survey in Greece, the corresponding outcome was $83 \%{ }^{26}$. Mathieu et al. ${ }^{22}$ reported a similar finding (75\%) in the French population. In our survey, the majority of the participants (89\%) partly to strongly agree that vaccines protect people from serious diseases, which also confirms previous Eurobarometer findings $(82 \%)^{26}$ and indicates the existence of high confidence in vaccines among the participants. Nevertheless, almost half of the participants (48\%) partly to strongly agree that vaccines often cause side effects, while in Eurobarometer survey in Greece the corresponding result was $35 \%{ }^{48}$. In a previous study in Germany, Walter et al. ${ }^{30}$ found that fear of adverse effects and lack of sufficient testing were the main concerns among those who oppose the use of influenza vaccines.

There were statistically significant differences, between genders, in the degree of agreement about vaccine safety. Males expressed a higher level of agreement concerning the view that vaccines are thoroughly tested before their approval, while females seem to agree more strongly that vaccines often cause side effects and that the spread of some new vaccines is mainly aimed at profit. Previous studies have shown a similar trend between genders on perceptions about vaccination ${ }^{28}$. It also was found that individuals $>30$ years seemed to express a relatively higher degree of agreement with the statement concerning the rigorous testing of vaccines prior to approval compared to those $\leq 30$ years. Participants aged $\leq 30$ years were also found to have a relatively higher degree of agreement with the economic feasibility behind the spread of some new vaccines compared to older participants. According to past studies, age was associated with increased probability of receiving the vaccination $^{16}$.

\section{Strengths and limitations}

In this study, several limitations should be taken into consideration. First, our results were acquired using online survey and inevitably people who do not use Internet were excluded. Second, the questionnaires were disseminated by email, as well as Messenger and Viber applications. The survey participants' synthesis has a bias in favor of females. The age group of $\geq 61$ years were not represented adequately and so the results on this age group should be carefully interpreted. The data were obtained from self-reported opinions without knowing the veracity of the participants' answers. Finally, our results should be interpreted taking into account the degree to which the survey sample was representative of the whole population. Despite the limitations, the study provides insights for decision-makers on strategic communication policy on vaccination.

\section{CONCLUSIONS}

Facing the biggest health crisis of the 21st century worldwide, with national healthcare systems under severe pressure to cope with the COVID-19 pandemic, vaccination is now gaining as an important measure to protect public health. Our results are in accordance with similar results of other international surveys. Accordingly, we consider that the public's beliefs in Greece with regard to vaccinations are not particularly different from those of other EU Member States. The majority of the participants are positive about vaccination. Healthcare professionals and official organizations are perceived as the preferred information sources on vaccination, suggesting that people rely on credible sources of information about vaccination. The strongest predictors of having a positive attitude towards vaccines was older age, and healthcare providers and official sources of health information. Participants with higher education and those using television as an information source were less likely to believe that vaccines frequently cause side effects. The present study suggests that official information bodies should intensify the communication efforts concerning the benefits of vaccination and vaccine safety and that this promotion should be directed towards younger individuals especially through the social networks.

\section{REFERENCES}

1. Lee SY, Hawkins R. Why Do Patients Seek an Alternative Channel? The Effects of Unmet Needs on Patients' HealthRelated Internet Use. J Health Commun. 2010;15(2):152166. doi:10.1080/10810730903528033

2. Alsyouf M, Stokes P, Hur D, Amasyali A, Ruckle H, Hu B. 'Fake News' in urology: evaluating the accuracy of articles shared on social media in genitourinary malignancies. BJU Int. 2019;124(4):701-706. doi:10.1111/bju.14787

3. Lavorgna L, De Stefano M, Sparaco M, et al. Fake news, influencers and health-related professional participation on the Web: A pilot study on a social-network of people with Multiple Sclerosis. Mult Scler Relat Disord. 2018;25:175-178. doi:10.1016/j.msard.2018.07.046

4. Chou WS, Oh A, Klein WMP. Addressing Health-Related Misinformation on Social Media. JAMA. 2018;320(23):24172418. doi:10.1001/jama.2018.16865

5. Byström E, Lindstrand A, Bergström J, Riesbeck K, Roth A. Confidence in the National Immunization Program among parents in Sweden 2016 - A cross- sectional survey. Vaccine. 2020;38(22):3909-3917. doi:10.1016/j.vaccine.2020.01.078

6. Broniatowski DA, Jamison AM, Qi S, et al. Weaponized Health Communication: Twitter Bots and Russian Trolls Amplify the Vaccine Debate. Am J Public Health. 2018;108(10):13781384. doi:10.2105/AJPH.2018.304567

7. Stone D. The 10 Inventions that Changed the World: The U.S. librarian of Congress ranks history's most important innovations. National Geographic. 2017. Accessed March 20, 2021. https://www.nationalgeographic.com/ magazine/2017/06/explore-top-ten-innovations/

8. Measles. World Health Organization. December 5, 2019. Accessed January 10, 2021. https://www.who.int/newsroom/fact-sheets/detail/measles 
9. Gianniki M, Siahanidou T, Botsa E, Michos A. Measles epidemic in pediatric population in Greece during 2017-2018: Epidemiological, clinical characteristics and outcomes. PLoS One. 2021;16(1):e0245512. doi:10.1371/journal.pone.0245512

10. Owens SR. Injection of confidence. The recent controversy in the UK has led to falling MMR vaccination rates. EMBO Rep. 2002;3(5):406-409. doi:10.1093/embo-reports/kvf106

11. Larson H, Leask J, Aggett S, Sevdalis N, Thomson A. A Multidisciplinary Research Agenda for Understanding Vaccine-Related Decisions. Vaccines 2013;1(3):293-304. doi:10.3390/vaccines1030293

12. Ratzan SC. Health literacy: communication for the public good. Health Promot Int. 2001;16(2):207-214. doi:10.1093/heapro/16.2.207

13. Burki T. Vaccine misinformation and social media. Lancet Digit Health. 2019;1(6):e258-259. doi:10.1016/S2589-7500(19)30136-0

14. Papazoglou A, Giamaiou K, Poulopoulou S, Pavlopoulou I. The National Vaccination Programme in Greece: Factors Affecting Parents' Knowledge. Glob J Med Res. 2013;13(3-K):1-12. Accessed January 20, 2022. https://globaljournals.org/ GJMR_Volume13/2-The-National-Vaccination-Programme. pdf

15. Tsagkas N, Siafaka V, Tzallas A, et al. Knowledge and beliefs about HPV infection and the relevant vaccination in Greek young population. Eur J Gynaecol Oncol. 2019;40(4):557562. doi:10.12892/ejgo4738.2019

16. Dardalas I, Pourzitaki C, Manomenidis G, et al. Predictors of influenza vaccination among elderly: a cross-sectional survey in Greece. Aging Clin Exp Res. 2020;32(9):1821-1828. doi:10.1007/s40520-019-01367-4

17. Mouchtouri VA, Agathagelidou E, Kofonikolas K, et al. Nationwide Survey in Greece about Knowledge, Risk Perceptions, and Preventive Behaviors for COVID-19 during the General Lockdown in April 2020. Int J Environ Res Public Health. 2020;17(23):8854. doi:10.3390/ijerph17238854

18. Skarpa EP. The role of libraries and information scientists in the disinformation and fake news era. Master's thesis. International Hellenic University; 2020.

19. Joshi A, Kale S, Chandel S, Pal DK. Likert Scale: Explored and Explained. Br J Appl Sci Technol. 2015;7(4):396-403. doi:10.9734/BJAST/2015/14975

20. Sullivan GM, Artino AR. Analyzing and Interpreting Data From Likert-Type Scales. J Grad Med Educ. 2013;5(4):541542. doi:10.4300/JGME-5-4-18

21. Weaver KF, Morales V, Dunn SL, Godde K, Weaver PF. An Introduction to Statistical Analysis in Research: With Applications in the Biological and Life Sciences. John Wiley \& Sons, Inc.; 2017. doi:10.1002/9781119454205

22. Mathieu P, Gautier A, Raude J, et al. Population perception of mandatory childhood vaccination programme before its implementation, France, 2017. Euro Surveill. 2019;24(25):1900053. doi:10.2807/1560-7917.ES.2019.24.25.1900053

23. Adlhoch C, Gomes Dias J, Bonmarin I, et al. Determinants of
Fatal Outcome in Patients Admitted to Intensive Care Units With Influenza, European Union 2009-2017. Open Forum Infect Dis. 2019;6(11):ofz462. doi:10.1093/ofid/ofz462

24. Iuliano AD, Roguski KM, Chang HH, et al. Estimates of global seasonal influenza-associated respiratory mortality: a modelling study. Lancet. 2018;391(10127):1285-1300. doi:10.1016/S0140-6736(17)33293-2

25. Michelozzi P, de’Donato F, Scortichini M, et al. Mortality impacts of the coronavirus disease (COVID-19) outbreak by sex and age: rapid mortality surveillance system, Italy, 1 February to 18 April 2020. Euro Surveill. 2020;25(19):pii=2000620. doi:10.2807/1560-7917.ES.2020.25.19.2000620

26. European Commission, Directorate-General for Health and Food Safety. Special Eurobarometer 478: Antimicrobial Resistance Report. European Commission; 2019. doi:10.2875/92205

27. Maltezou HC, Theodora M, Lytras T, et al. Knowledge, attitudes and practices about vaccine-preventable diseases and vaccinations of children among pregnant women in Greece. Vaccine. 2020;38(48):7654-7658. doi:10.1016/j.vaccine.2020.10.003

28. Reiter PL, Pennell ML, Katz ML. Acceptability of a COVID-19 vaccine among adults in the United States: How many people would get vaccinated? Vaccine. 2020;38(42):6500-6507. doi:10.1016/j.vaccine.2020.08.043

29. Campbell H, Edwards A, Letley L, Bedford H, Ramsay M, Yarwood J. Changing attitudes to childhood immunisation in English parents. Vaccine. 2017;35(22):2979-2985. doi:10.1016/j.vaccine.2017.03.089

30. Walter D, Böhmer MM, Reiter S, Krause G, Wichmann 0 . Risk perception and information-seeking behaviour during the 2009/10 influenza A(H1N1)pdm09 pandemic in Germany. Euro Surveill. 2012;17(13):pii=20131. doi:10.2807/ese.17.13.20131-en

31. International Federation of Library Associations and Institutions. How to Spot Fake News - COVID-19 Edition. IFLA; 2021. Accessed July 8, 2021. https://repository.ifla. org/handle/123456789/1289

32. Meppelink CS, Smit EG, Fransen ML, Diviani N. "I was Right about Vaccination": Confirmation Bias and Health Literacy in Online Health Information Seeking. J Health Commun. 2019;24(2):129-140. doi:10.1080/10810730.2019.1583701

33. Hwang J, Shah DV. Health Information Sources, Perceived Vaccination Benefits, and Maintenance of Childhood Vaccination Schedules. Health Commun. 2019;34(11):12791288. doi:10.1080/10410236.2018.1481707

34. Karafillakis E, Larson HJ. The benefit of the doubt or doubts over benefits? A systematic literature review of perceived risks of vaccines in European populations. Vaccine. 2017;35(37):4840-4850. doi:10.1016/j.vaccine.2017.07.061

35. Wagner AL, Huang Z, Ren J, et al. Vaccine Hesitancy and Concerns About Vaccine Safety and Effectiveness in Shanghai, China. Am J Prev Med. 2021;60(1)(Suppl 1):S77-S86. doi:10.1016/j.amepre.2020.09.003

36. Siani A. Measles outbreaks in Italy: A paradigm of 
the re-emergence of vaccine-preventable diseases in developed countries. Prev Med. 2019;121:99-104. doi:10.1016/j.ypmed.2019.02.011

\section{ACKNOWLEDGEMENTS}

The authors would like to acknowledge Konstantinos B. Simoglou for providing technical help, as well as those who participated in this study.

\section{CONFLICTS OF INTEREST}

The authors have completed and submitted the ICMJE Form for Disclosure of Potential Conflicts of Interest and none was reported.

\section{FUNDING}

There was no source of funding for this research.

\section{ETHICAL APPROVAL AND INFORMED CONSENT}

The study is non-medical research that did not involve human subjects testing. The study was approved by the General Assembly (GA) of the Department of Library Science, Archives and Information Systems, School of Social Sciences, International Hellenic University (GA Meeting Number: 5th GA, 14 May, 2020/MSc/Subject 8-Research No.23).

\section{DATA AVAILABILITY}

The data supporting this research are available from the authors on reasonable request.

\section{AUTHORS' CONTRIBUTIONS}

PES: data acquisition, data analysis and interpretation, drafting and revising the manuscript. EG: conceptualizing the study, designing the research, revising and approving the manuscript.

\section{PROVENANCE AND PEER REVIEW}

Not commissioned; externally peer reviewed. 